\title{
Arguments by Parallels in the Epistemological Works of Phya pa Chos kyi seng ge
}

\author{
Pascale Hugon
}

Published online: 6 February 2008

(C) Springer Science+Business Media B.V. 2008

\begin{abstract}
The works of the Tibetan logician Phya pa Chos kyi seng ge (1109-1169) make abundant use of a particular type of argument that I term 'argument by parallels'. Their main characteristic is that the instigator of the argument, addressing a thesis in a domain A, introduces a parallel thesis in an unrelated domain B. And in the ensuing dialogue, each of the instigator's statements consists in replicating his interlocutor's previous assertion, mutatis mutandis, in the other domain (A or B). I show that such a dialogue involves two parallel arguments that develop in an intersecting zigzag pattern, and discuss the principles involved in the establishment of the conclusion from the perspective of parity of reasoning and analogical argument. I examine the overall rhetorical strategy directing the use of arguments by parallels and the pedagogical and explanatory functions they can serve. I also evaluate the plausibility of their use in Phya pa Chos kyi seng ge's works mirroring a contemporary practice of oral debate, and reflect on the status of such arguments in the framework of Indo-Tibetan logic.
\end{abstract}

Keywords Phya pa Chos kyi seng ge - Tibetan - Logic $\cdot$ Argument by parallels . Rhetorical strategy · Debate

\section{Introduction}

The Tibetan thinker Phya (/Phywa) pa Chos kyi seng ge (1109?-1169) (hereafter: Phya pa [tcha-ba] $)^{1}$, played a key role in the development of the Tibetan tradition of

\footnotetext{
1 About Phya pa's life and works, see van der Kuijp (1978, 1983, Chap. 2).

P. Hugon

University of Lausanne, Vaud, Lausanne, Switzerland

P. Hugon $(\bowtie)$

Austrian Academy of Sciences, Institute for the Cultural and Intellectual History of Asia,

Prinz-Eugen-Strasse 8-10, 1040 Vienna, Austria

e-mail: pascale.hugon@assoc.oeaw.ac.at
} 
logic and epistemology, a tradition that has been kept alive up to the present day. While based on the foundational works of the Indian thinkers Dignāga (6th c.) and Dharmakīrti (7th c.), the Tibetan tradition displays an individual character by its use of indigenous methods of expositions, the development of its own technical terminology and of logical inquiries into new topics, as well as through its novel understanding of the thought of the Indian founding fathers. Phya pa is especially famous for original interpretations that were instrumental to the subsequent development of Tibetan epistemology. In addition, the tradition also ascribes to him certain innovations in the field of debate, namely a method of argumentation by chains of consequences (thal phreng). ${ }^{2}$ This method, although widely attested in Tibetan works from the fifteenth century ${ }^{3}$, turns out to be conspicuously absent in the Dispeller of the Darkness of Mind and the Sunray of Wisdom, two works of Phya pa on epistemology that have been re-discovered only recently. ${ }^{4}$ Nevertheless, Phya pa's treatises do attest to a number of original features, both with regard to the positions held by the author (many of which stand out as rather unorthodox interpretations of Dharmakīrti's thought) and to his argumentative style. Concerning the latter, Phya pa's epistemological works profusely employ a particular type of argument that takes the form of a dialogue, the main characteristic of which is that the answers of one of the debaters all consist in parallel statements that replicate his interlocutor's previous assertion, mutatis mutandis, in another (usually completely unrelated) domain. ${ }^{5}$ This quite unique and somewhat bewildering style of argumentation, which I have termed argumentation "by parallels", is, to my knowledge, absent from Indian epistemological literature, and does not appear to

\footnotetext{
2 This claim seems to have originated with Stcherbatsky, who however appears to be merely repeating a traditional attribution. "The first author to compose an independent work on logic is Chaba-choikyi-senge (1109-1169). He is the creator of a special Tibetan logical style..." (Stcherbatsky, 1994, p. 55) and "A special literary style has been created for the brief formulation of such a chain of reasoning, it is called the method of 'sequence and reason' and its establishment is ascribed to the lama Chaba-choikyi-senge" (ibid. 58).

${ }^{3}$ Argumentation by chains of consequences, each of which takes the form "this follows (thal), because of that (phyir)", is one of the formal characteristics of the so-called "bsdus grwa" literature and of Tibetan handbooks for debate (yig cha). An early occurrence of argumentation by chains of consequences is attested in a fourteenth century work by Bu ston (1290-1364), whereas the earliest available bsdus grwa work, the Rwa stod bsdus grwa by 'Jam dbyangs mChog lha 'od zer (1429-1500), dates to the middle of the fifteenth century. It is notable that the structure and contents of this work and other bsdus grwa manuals differ significantly from the works of Phya pa, thus annulling another widely held ascription to Phya pa, namely the paternity of bsdus grwa literature.

${ }^{4}$ The works of Phya pa were, until recently, considered lost, and the ideas of this philosopher were known to us only through the accounts and/or criticism of later authors. Sixteen of his works have been recovered at the monastery of 'Bras spungs and are now available as part of a collection of works by early bKa' gdams pa authors published in facsimile in Chengdu in $b K a$ ' gdams gsung 'bum phyogs sgrig thengs dang po'. Volume 8 of this collection contains three works of Phya pa on epistemology: a summarized exposition of Dharmakirti's thought entitled "Epistemology, the Dispeller of the Darkness of Mind" (Tshad ma yid kyi mun sel) (hereafter: Dispeller), a commentary on Dharmakìrti's Pramānaviniścaya, the "Sunray of wisdom that penetrates the difficult points of reasoning and formulation, an extensive commentary of the Pramānaviniścaya" (Tshad ma rnam par nges pa'i 'grel bshad yi ge dang rigs pa' $\mathrm{i}$ gnad la 'jug pa'i shes rab kyi 'od zer) (hereafter: Sunray of Wisdom), and a topical outline of the same work (Tshad ma rnam par nges pa'i bsdus don). This paper is based on textual material from the first two (Phya pa Chos kyi seng ge 2006a, b).

${ }^{5}$ Phya pa's Dispeller includes no less than 65 occurrences of such arguments in its 96 folios (the equivalent of about 200 typed pages in transcription).
} 
have enjoyed much popularity in later Tibetan literature. In this paper, I will first describe the generic features of these arguments on the basis of the instances that can be found in the Dispeller and the Sunray of Wisdom, and present one case as an illustration. I will then attempt to characterize and evaluate these arguments in view of the function that Phya pa ascribes to them, and shall also reflect on their use against the background of the theoretical rules for correct proofs and refutations prescribed in Indo-Tibetan literature and by the author himself.

\section{The Structure of Arguments by Parallels}

\subsection{Generic Features}

Arguments by parallels can be characterized by their structure as well as by their specific syntax and associated terminology. They take the form of a dialogue between the debater initiating the argument, who I will call the "instigator" (I), and the debater who I will call the "respondent" (R). ${ }^{6}$ One can distinguish three stages in their discussion: (i) an initial stage (Sect. 2.1.1), (ii) an intermediate development (Sect. 2.1.2), (iii) a final stage (Sect. 2.1.3).

\subsubsection{The Initial Stage}

The initial stage of the argument starts with the statement of a thesis $\mathbf{P}$ under discussion. The thesis $\mathbf{P}$, which stands as the instigator's target, represents either an objection to the instigator's own position by a real or hypothetical opponent, or a philosophical tenet held by another philosopher. Accordingly, the thesis $\mathbf{P}$ is stated either in a conditional form - "if one were to state..." (...smra na; ...zhe na; ...brjod $n a)$, "if one were to admit..." (...'dod na), or "if one were to object..." (...rgol na)_ or as an independent sentence reporting somebody's position (...zhes zer ba) followed by an expression like "in such a case" (de Ita na, de ltar na, de 'dod na).

The first characteristic of arguments by parallels is that the instigator does not address the thesis $\mathbf{P}$ directly, but rather retorts to it with a parallel thesis $\mathbf{P}^{\prime}$. $\mathbf{P}^{\prime}$ is frequently introduced by the verb mgo sgre, or simply sgre (that I translate in this context as "to retort"), which conveys the idea of "repetition" or "analogy". The

\footnotetext{
6 These terms are introduced here to distinguish the respective roles of the debaters, but they do not correspond to Tibetan terms. I intentionally avoid the existing appellations "proponent/opponent" ([snga] rgol ba/phyi rgol), questioner/answerer (rtsod pa poldam bca' ba) etc., as they would be confusing in this context.

7 This verb occurs under various orthographies: mgo sgre, mgo bsgre, 'go (b)sgre. The Bod-rgya dictionary explains mgo bsgre as rigs mtshungs sbyar ba'am rigs mtshungs par byas pa ("analogical application or analogy") (Zhang Yisun 1985). Goldstein et al. (2001) gives for mgo sgre the synonym rig 'gre and its homophones rigs 'gre and rigs (b)sgre, translating them with "logical reasoning/inference", whereas he gives as the first meaning of the verb 'gre: "to reason by analogy" (the second meaning being "to roll over"). Jäschke gives for sgre and 'gre "to roll (over)" as the first meaning, and "to repeat" as the second (Jäschke 1995). Das for his part distinguishes the meanings of the homophones 'gre "to roll (over)", and sgre "to repeat" (Sarat Chandra Das 1992).
} 
expression mgo sgre is also used by Phya pa as a name for the argument by parallels as a whole. ${ }^{8}$ The Tibetan term sgre corresponds to the Sanskrit "atideśa", a term used notably in logic, medicine and grammar to denote the transfer of a property, rule, or prescription, etc., to something else. ${ }^{9}$ However, in only a limited number of the arguments by parallels found in Phya pa's works does the parallel statement $\mathbf{P}^{\prime}$ keep a common attribute with $\mathbf{P}$. These cases, in which the instigator retorts for instance to a thesis $\mathbf{P}$ of the form " $\mathrm{A}$ is $\mathrm{X}$ " with a statement $\mathbf{P}^{\prime}$ of the form " $\mathrm{B}$ also is $\mathrm{X}$ ", bear the specific heading of mtshungs pa (literally: "similarity"). ${ }^{10} \mathrm{In}$ the majority of arguments by parallels, no property from $\mathbf{P}$ is retained in $\mathbf{P}^{\prime}$. The relevance of $\mathbf{P}^{\prime}$ is only a matter of the preservation of the formal structure of $\mathbf{P}$, that is to say, of the relations between the constitutive elements of $\mathbf{P}$. There is thus no domain constraint as to the choice of the retort-thesis $\mathbf{P}^{\prime}$. In Phya pa's texts, cows or plants are frequently selected for this role-making these arguments quite startling at first. Consider for instance the reply offered to an opponent contesting the validity of inference, saying:

Inference cannot be the comprehension of something true (i.e. it cannot be a valid cognition) because it is a wrong cognition insofar as, depending on a concept, it is erroneous with regard to what is apprehended.

Phya pa initiates an argument by parallels with the following retort:

A sprout could not be the cause of a visual cognition, because it emerges subsequently with regard to the seed. ${ }^{11}$

Although logic and botany are two quite distinct domains, both the initial statement and the retort instantiate the structure " $\mathrm{A}$ is not $\mathrm{B}$ because it is $\mathrm{X}$ with regard to $\mathrm{Y}$ ".

In order for the argument to be continued past the initial stage, it is additionally necessary that the instigator's $\mathbf{P}^{\prime}$ is a statement that motivates a response from his

\footnotetext{
${ }^{8}$ See for instance Phya pa Choa kyi seng ge (2006a, 29b4) where such an argument occurs in a section entitled mgo bsgres dgag pa "refutation by (a) mgo bsgre".

${ }^{9}$ Cf. Oberhammer et al. (1991, p. 22): "Der Terminus bezeichnet das Darlegen von etwas, indem man auf etwas an anderer Stelle Vorgetragenes hinweist und dieses in die gegenständliche Darlegung einbezieht, ohne es nochmals vorzutragen". In the Abhidharmakośabhāsya ad I.39 for instance, the Sanskrit original "atideśa" is translated as "bsgre ba" (For the Tibetan, see sDe dge 4090, 46b7). In this passage, the "transfer" (atideśa) consists in the attribution of the conclusion reached for visible form to the cases of sound, odour, taste and touch, namely that they are "common" (sabhagga). The opponent argues that being "common" can be said of sound, which, like visible form, is perceived at a distance and can be perceived by many people, but not of odour, taste and touch that are not perceived at a distance, but only when they enter a close relation with the respective sense-faculty. Hence the transfer of the property "common" must be done with regard to the organ, not the object (Vasubandhu $(1967$, p. 28, 15) :bhavatu śabda evam. gandhādayas tu ya ekena grhyante na te 'nyena prāptagrahañād ity asādhāranatvād eșām cakșurādivad atideśo nyāyyah).

${ }^{10}$ For instance, in the context of the refutation of idealism, someone objects to the proposition that "pleasure and pain are easily distinguished through experience" with the retort that "white and the visual cognition of white are easily distinguished through experience". Cf. Phya pa Choa kyi seng ge (2006a, 3a5-3a6) under the heading "bde sdug dang mtshungs pa" (similarity with [the case of] pleasure and pain): bde sdug rdzas tha dad par cis nges $\mid$ myong pas nges so zhe na | dkar po dang myig shes tha dad par yang myong pas nges so...

${ }^{11}$ Phya pa Choa kyi seng ge (2006a, 33b9-34a1) : rjes dpag don spyi la ltos nas gzung pa la 'khrul pa' $i$ log shes yin pas de ${ }_{34 a 1}$ la bden pa rtogs pas ma khyab po zhe na $\mid$ myu gu sa bon la ltos te phyis 'byung yin pas myig gi rnam shes kyi rgyu ma yin par 'gyur ro.
} 
interlocutor. This is most likely to be the case if $\mathbf{P}^{\prime}$ is a thesis to which the respondent does not subscribe. As a way to prompt a response, the parallel statement $\mathbf{P}^{\prime}$ is then often stated within a challenging question, such as "how would you refute $\mathbf{P}^{\prime}$ ?", "what would you say to someone who holds $\mathbf{P}^{\prime}$ ?" and so on. Another situation that is seen to prompt a response is the respondent's acknowledgement, disregarding whether or not he himself admits $\mathbf{P}^{\prime}$, that $\mathbf{P}^{\prime}$ contradicts other tenets in the instigator's system.

\subsubsection{The Intermediate Development}

The initial stage, in which the instigator presents the incriminated thesis $\mathbf{P}$ and the retort $\mathbf{P}^{\prime}$, is followed by a number of intermediate steps (in Phya pa's texts, usually two to four), each of which consists in a statement $\mathbf{S}_{\mathbf{n}}$ of the respondent followed by a statement $\mathbf{S}_{\mathbf{n}}^{\prime}$ of the instigator. Both debaters follow implicit rules that determine the distinctive structure of arguments by parallels:

- The respondent addresses the previous statement $\mathbf{S}_{\mathbf{n}-\mathbf{1}}^{\prime}$ of the instigator directly. He can do it with a question, an entailment, an absurd consequence, an exemplification, or suchlike. His choice of answer will decide the course of the discussion.

- The instigator, who, in the initial stage, retorted to the thesis $\mathbf{P}$ with a parallel statement $\mathbf{P}^{\prime}$, repeats this technique at each step of the intermediate development. Thus, each statement $\mathbf{S}_{\mathbf{n}}^{\prime}$ of the instigator is parallel to the previous statement $\mathbf{S}_{\mathbf{n}}$ of the respondent. The parallelism is sometimes underlined by expressions such as "just like in the previous case..." (snga ma ltar na'ang, snga ma nyid bzhin, snga ma bzhin, snga ma'ang de dang 'dra'o...), which occasionally substitute for the full formulation of the parallel statement. The use of the verb "to retort" (mgo sgre) is however restricted to the initial stage. Just as in the initial stage, the parallelism between $\mathbf{S}_{\mathbf{n}}^{\prime}$ and $\mathbf{S}_{\mathbf{n}}$ is a matter of structure, not of common or similar elements. In the intermediate development, no new domain is introduced for the parallels; the instigator remains within the two domains introduced in the initial stage, namely that of the thesis and that of the retort (D and $\mathbf{D}^{\prime}$ ). Hence, when the respondent's statement $\mathbf{S}_{\mathbf{n}}$ concerns the initial domain $\mathbf{D}$, the instigator states a parallel $\mathbf{S}_{\mathbf{n}}^{\prime}$ in domain $\mathbf{D}^{\prime}$, and when $\mathbf{S}_{\mathbf{n}}$ concerns the parallel domain $\mathbf{D}^{\prime}$, the parallel $\mathbf{S}_{\mathbf{n}}^{\prime}$ brings the discussion back to the initial domain D. The instigator's statements thus always induce a change of domain, whereas the respondent's statements remain within the domain of the previous statement of the instigator (alternatively $\mathbf{D}$ and $\mathbf{D}^{\prime}$ ).

\subsubsection{The Final Stage}

The argumentation by parallels against a thesis $\mathbf{P}$ is not always successful for its instigator. The respondent can indeed manage to show that $\mathbf{P}$ and $\mathbf{P}^{\prime}$ are in fact not parallel. The nature of the final stage differs accordingly: 
Successful for the instigator. The final stage is in this case the point where the instigator draws a parallel statement $\mathbf{S}_{\mathbf{f}}^{\prime}$ concerning the initial domain of discussion (D) to which the respondent cannot object further. When dealing with written arguments, it appears rather as the point where the respondent is not given an opportunity to object further. Let us note that the instigator's final statement does not in itself refute the incriminated thesis $\mathbf{P}$, but is part of the reasons in support of its refutation. ${ }^{12}$ An example of such an outcome will be illustrated in the argument by parallels analyzed below.

Unsuccessful for the instigator. An argument is unsuccessful for its instigator when, in parallel to an absurd consequence $\mathbf{S}_{\mathbf{f}}$ relative to the parallel domain $\mathbf{D}^{\prime}$ stated by the respondent, the instigator draws as a parallel a consequence $\mathbf{S}_{\mathbf{f}}^{\prime}$ relative to domain $\mathbf{D}$ that consists in a view which the respondent actually subscribes to. In this case, the respondent ends the argument with the remark: "since we admit that, how is it similar?" ('dod pa nyid yin pas ga la mtshungs). This statement retrospectively shows that the putative parallel $\mathbf{P}^{\prime}$ was in fact not parallel to $\mathbf{P}$. Hence $\mathbf{P}$ remains unchallenged by the initial retort. ${ }^{13}$

\section{Successful}

$\mathrm{R}$

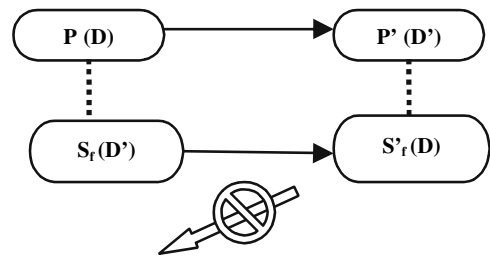

Unsuccessful

$\mathrm{R}$

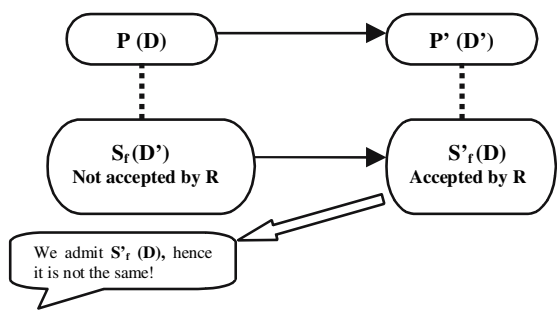

12 The same can be said of the respondent's statement $\mathbf{S}_{\mathbf{f}}$ in the final stage: it is part of the reasons that support the rejection of $\mathbf{P}^{\prime}$, without constituting a refutation in itself.

13 Such a situation is illustrated for instance in an argument where the domain of "negation" is introduced in parallel to the domain of "affirmation". Namely, the instigator retorts to the thesis $\mathbf{P}$ "by negating impermanence with regard to permanence in general, one negates impermanence with regard to a permanent demon's pot" with the parallel $\mathbf{P}^{\prime}$ "by establishing the association of existence with pot in general, one establishes the association of existence with a permanent demon's pot" (in other words, by proving that pot in general exists, one proves that a permanent demon's pot also exists). After a few steps of intermediate development, the respondent comes up with an absurd consequence relative to domain $\mathbf{D}^{\prime}$ (the domain of affirmation), namely that establishing that there is smoke in the kitchen entails the establishment that there is mountain's smoke in the kitchen (more literally: "establishing the association of 'kitchen' and the universal 'smoke' would entail the establishment of the association of 'kitchen' and 'mountain's smoke""). The instigator then draws the parallel for domain D (the domain of negation), namely that negating that there is smoke in the river entails negating that there is mountain's smoke in the river (more literally: "negating the association of 'river' and the universal 'smoke' would entail the negation of the association of 'river' with 'mountain's smoke""). This is meant to be an absurd consequence by the instigator, but the respondent actually admits this, and hence can claim that the two cases are not similar. See Phya pa Chos kyi seng ge (2006a, 93b3-93b5). 
Predictably enough, in Phya pa's texts, arguments by parallels always end up successfully when the instigator is Phya pa himself and always fail when Phya pa plays the role of the respondent.

\subsection{Intersecting Arguments}

The sequence of statements in an argument by parallels takes the form: $\mathbf{P}, \mathbf{P}^{\prime}, \mathbf{S}_{\mathbf{1}}$, $\mathbf{S}_{1}^{\prime}, \mathbf{S}_{\mathbf{2}}, \mathbf{S}_{2}^{\prime} \ldots \mathbf{S}_{\mathbf{n}}, \mathbf{S}_{\mathbf{n}}^{\prime}, \mathbf{S}_{\mathbf{n}+\mathbf{1}}, \mathbf{S}_{\mathbf{n}+\mathbf{1}}^{\prime} \ldots \mathbf{S}_{\mathbf{f}}, \mathbf{S}_{\mathbf{f}}^{\prime}$. The nature of the successive $\mathbf{S}_{\mathbf{n}}$ and $\mathbf{S}_{\mathbf{n}}^{\prime}$ in the intermediate development (as described in Sect. 2.1.2) has a notable consequence: since each statement $\mathbf{S}_{\mathbf{n}}^{\prime}$ of the instigator (I) is parallel to a statement $\mathbf{S}_{\mathbf{n}}$ of the respondent $(\mathbf{R})$, and since this statement $\mathbf{S}_{\mathbf{n}}$ constitutes a response to the previous statement $\mathbf{S}_{\mathbf{n}-\mathbf{1}}^{\prime}$ of the instigator, which is itself parallel to the respondent's statement $\mathbf{S}_{\mathbf{n}-\mathbf{1}}, \mathbf{S}_{\mathbf{n}}^{\prime}$ provides, indirectly, an answer to the statement $\mathbf{S}_{\mathbf{n}-\mathbf{1}}$ uttered by the respondent at the previous level.

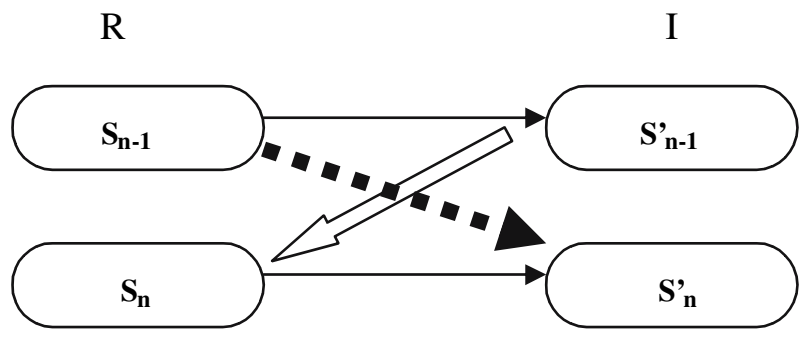

As the process repeats, we can actually distinguish two arguments that develop in intersecting zigzag patterns: a first argument $\mathbf{T}$ pertaining to the domain $\mathbf{D}$ follows the sequence: $\mathbf{P}, \mathbf{S}_{\mathbf{1}}^{\prime}, \mathbf{S}_{\mathbf{2}}, \mathbf{S}_{\mathbf{3}}^{\prime}, \mathbf{S}_{\mathbf{4}}, \mathbf{S}_{\mathbf{5}}^{\prime} \ldots$, whereas a second argument $\mathbf{T}^{\prime}$, pertaining to the domain $\mathbf{D}^{\prime}$, follows the sequence: $\mathbf{P}^{\prime}, \mathbf{S}_{\mathbf{1}}, \mathbf{S}_{\mathbf{2}}^{\prime}, \mathbf{S}_{\mathbf{3}}, \mathbf{S}_{\mathbf{4}}^{\prime}, \mathbf{S}_{\mathbf{5}} \ldots$ While the respective steps of $\mathbf{T}$ and $\mathbf{T}^{\prime}$ are parallel, the two debaters play mirroring roles: in $\mathbf{T}, \mathbf{R}$ is the proponent and $\mathbf{I}$ the opponent, and in $\mathbf{T}^{\prime}, \mathbf{I}$ is the proponent and $\mathbf{R}$ the opponent (see the table at the end of Sect. 2.3 for a concrete example). In the case of a successful argument, the final statement $\mathbf{S}_{\mathbf{f}}^{\prime}$ of the initiator is parallel to the previous statement $\mathbf{S}_{\mathbf{f}}$ of the respondent and follows it directly in the sequence of the argument by parallels. But $\mathbf{S}_{\mathbf{f}}^{\prime}$ is also the last step of $\mathbf{T}$, and in this regard follows $\mathbf{S}_{\mathbf{f}-\mathbf{1}}$. When considering the refutation of the initial thesis $\mathbf{P}$, one thus has to take into account two dimensions: a vertical one-the argument $\mathbf{T}$, and a horizontal one-the systematic parallels, which involve the interplay of $\mathbf{T}$ and $\mathbf{T}^{\prime}$.

\subsection{Example of an Argument by Parallels}

In order to illustrate the features described above, I now turn to an argument by parallels initiated by Phya pa that pertains to a topic closely related to the central theme of Buddhist epistemological works - that of valid cognitions (Skt. pramāna, 
Tib. tshad ma), namely the question of the ascertainment of their validity. This argument consists in the following set of statements: ${ }^{14}$

Respondent (=Mīmāṃsaka)

P All valid cognitions (A) are intrinsically ascertained $(\mathbf{X})$

$\mathbf{S}_{\mathbf{1}}$ The appearance of two moons ( $\left.\mathbf{e}^{\prime}\right)$ would be a $\mathbf{S}_{1}$ perception $\left(\mathbf{X}^{\prime}\right)$, because it is non-conceptual $\left(\mathbf{A}^{\prime}\right)$

$\mathbf{S}_{\mathbf{2}}$ [A cognition] that ascertains that fire appears but does not ascertain its reality (e) is not a valid cognition (A)

$\mathbf{S}_{\mathbf{3}}$ If the appearance of two moons $\left(\mathbf{e}^{\prime}\right)$ is not non-conceptual $\left(\mathbf{A}^{\prime}\right)$, it is contradictory to its being vividly appearing $\left(\mathbf{G}^{\prime}\right)$

$\mathbf{S}_{\mathbf{4}}$ We admit that the cognition that ascertains fire but not its truth (e) is intrinsically ascertained $(\mathbf{X})$

$\mathbf{S}_{\mathbf{5}}$ The appearance of two moons $\left(\mathbf{e}^{\prime}\right)$ is not a perception $\left(\mathbf{X}^{\prime}\right)$, because it is not nonerroneous with regard to the apprehended state of affairs $\left(\mathbf{L}^{\prime}=\operatorname{def}\left[\mathbf{X}^{\prime}\right]\right)$
Instigator (=Phya pa)

$\mathbf{P}^{\prime} \quad$ All non-conceptual cognitions $\left(\mathbf{A}^{\prime}\right)$ are perceptions $\left(\mathbf{X}^{\prime}\right)$

$\mathbf{S}_{\mathbf{1}}^{\prime}$ [A cognition] that ascertains that fire appears but does not ascertain its reality (e) would be intrinsically ascertained [as valid] $(\mathbf{X})$, because it is a valid cognition (A)

$\mathbf{S}_{\mathbf{2}}{ }_{\mathbf{2}}$ The appearance of two moons $\left(\mathbf{e}^{\prime}\right)$ is not nonconceptual $\left(\mathbf{A}^{\prime}\right)$

$\mathbf{S}_{3}^{\prime}$ If the cognition that ascertains fire but not its truth (e) is not a valid cognition (A), it is either an unascertained appearance $(\mathbf{B})$ or the cognition of something already known (C); the two options have been refuted earlier

$\mathbf{S}_{\mathbf{4}}^{\prime}$ We admit that the appearance of two moons $\left(\mathbf{e}^{\prime}\right)$ is a perception $\left(\mathbf{X}^{\prime}\right)$

$\mathbf{S}^{\prime}{ }_{5}$ The cognition that ascertains fire but not its truth (e) is not intrinsically ascertained $(\mathbf{X})$, because it does not ascertain by itself the possession of the definiens of valid cognition, insofar as doubt with regard to the object being a superimposition prevents the establishment that the apprehending cognition is non-erroneous with regard to the actual state of affairs $(\mathbf{L}=\operatorname{def}[\mathbf{X}])$

Although the analysis that follows will focus on the structure of the argument, a few words of introduction concerning its contents is de rigueur. Buddhist logicians usually agree that valid cognition is of two sorts, perception and inference. The question of the ascertainment of their validity, not raised by Dharmakîrti, is an issue that his successors examine, adopting various positions as to what it means to ascertain the validity of a cognition, as well as to which types of cognition are to be characterized as being intrinsically or, respectively, extrinsically ascertained as valid. To make a long story short, Phya pa's position on the subject is that the ascertainment of validity amounts to the determination that the cognition under consideration has the definiens of a valid cognition, and that, at least in some cases, a distinct cognition is required to ascertain this fact. ${ }^{15}$ The classical example given

\footnotetext{
14 The Tibetan text and a translation can be found in the appendix. The same argument is found also in Phya pa Chos kyi seng ge (2006b, 31a5).

15 For Phya pa, the definiens of valid cognition encompasses several characteristics, among which that it must be novel, it must eliminate opposite superimpositions, and that it must be non-erroneous with regard to the state of affairs (i.e., cognition is not found in the absence of the state of affairs). Of these characteristics, novelty and the ability to eliminate superimpositions are held to be always intrinsically
} 
for an extrinsically ascertained valid cognition is the visual cognition of an object identifiable as a fire, in which a doubt remains as to whether the "fire" that appears is a real fire or a magical illusion. ${ }^{16}$

Phya pa seeks to refute the view of philosophers (identified as Indian followers of the Mīmāmsā tradition) who, for their part, contend that validity is always ascertained intrinsically. The statement "all valid cognitions are intrinsically ascertained as valid" thus stands as the thesis $\mathbf{P}$ under discussion, and its domain is the ascertainment of validity (D). Since this statement $\mathbf{P}$ expresses a universal relation between the property A "being a valid cognition" and the property $\mathbf{X}$ "being intrinsically ascertained as valid", Phya pa's retort, in the initial stage, likewise illustrates a universal relation between two properties. Since any domain can be chosen for the parallel statement, Phya pa could have retorted for instance that "all animals are mammals", a statement expressing a universal relation to which no interlocutor would likely subscribe. ${ }^{17}$ Instead, Phya pa chooses a parallel in the domain of perception $\left(\mathbf{D}^{\prime}\right)$, stating as $\mathbf{P}^{\prime}$ : "all non-conceptual cognitions are perceptions". Like $\mathbf{P}, \mathbf{P}^{\prime}$ expresses a universal relation between two properties, namely "being non-conceptual" $\left(\mathbf{A}^{\prime}\right)$ and "being a perception" $\left(\mathbf{X}^{\prime}\right)$. Here again, it is not necessary to go into the details of the theory of perception. All we need to know is that Phya pa does not himself hold $\mathbf{P}^{\prime}$, for he accepts that there are cases of non-conceptual cognition that fail to qualify as perceptions. A classical example of such a case is the non-conceptual cognition in which two moons appear. This "appearance of two moons" falls short of being a perception because in reality there are not two moons. Hence, such a cognition lacks one of the conditions that Phya pa includes in the definiens of perception, namely it is not "non-erroneous with regard to the apprehended state of affairs". 18

The intermediate steps of the argument can now be understood as follows:

$\mathbf{S}_{\mathbf{1}}$ The respondent points to the absurd consequence that $\mathbf{P}^{\prime}$ would have in the case of the counter-example just discussed, namely the cognition in which two moons appear $\left(\mathbf{e}^{\prime}\right)$. Indeed, if all non-conceptual cognitions were perceptions

Footnote 15 continued

ascertained. On the other hand, the characteristic of being "non-erroneous with regard to the state of affairs" may necessitate another cognition for its ascertainment in cases when there remains doubt as to the reality of what is perceived, in other words as to the existence of a corresponding state of affairs. Such a doubt is only likely to occur when an object is perceived for the first time. For more details see Hugon (forthcoming).

16 See Phya pa Chos kyi seng ge (2006a, 36b9-37a1): rgyang ring po na kha dog dmar la 'bar ba'i kha dog can gyi me yod pa snang pa na snang par nges kyang ci kho bo ${ }_{37 a}$ la mer snang pa 'di bden nam sgyu ma mkhan gyis sprul pa lasogs pa brdzun pa yin zhes the tsom za bas blo rang nyid bden pa 'jal bar ma nges pa lta bu'o $\|$

17 Actually, one does find an alternative formulation of this same argument in a text reporting Phya pa's refutation of the Mīmāṃsaka. Phya pa is said to present as an initial retort "all logical reasons establishing an entity would be reasons qua effects". See Klong chen Rab 'byams pa (2000, 128-129).

18 The position that not all non-conceptual cognitions qualify as perception is shared by Dharmakīti's interpreters, since Dharmakīti defined perception as "devoid of conceptualization and non-erroneous" (Pramānaviniścaya I.4a = Nyāyabindu I.4a: pratyakșạ̣ kalpanāpodham abhrāntam). Note however that Phya pa's definition varies slightly from Dharmakīti's, as he adds the qualification "non-erronous with regard to the apprehended state of affairs" (gzung don la ma 'khrul ba). For more details about Phya pa's views on perception, see Hugon (forthcoming). 
(all $\mathbf{A}^{\prime}$ s are $\mathbf{X}^{\prime}$ ), the cognition in which two moons appear would also qualify as perception. This, however, is contradictory to the instigator's tenets.

$\mathbf{S}_{\mathbf{1}}^{\prime}$ The instigator draws a parallel in the domain of the ascertainment of validity (D) on the basis of (what he holds to be) a counter-example to $\mathbf{P}$ (=all As are $\mathbf{X}$ ), that is to say a case of valid cognition that is not intrinsically ascertained. As a counter-example (e), he states the classical example of the perception of a fire in which a doubt remains as to the truth of the fire perceived.

$\mathbf{S}_{\mathbf{2}}$ The respondent, who for his part does not admit that there is a counterexample to $\mathbf{P}$, seeks to reject the absurd consequence pertaining to domain $\mathbf{D}$ by rejecting the antecedent "e is a valid cognition" ( $\mathbf{e}$ is $\mathbf{A}$ ).

$\mathbf{S}_{\mathbf{2}}^{\prime}$ Parallel to this, the instigator rejects the antecedent of the absurd consequence stated earlier for domain $\mathbf{D}^{\prime}$, namely that the cognition in which two moons appear is non-conceptual ( $\mathbf{e}^{\prime}$ is $\mathbf{A}^{\prime}$ ).

$\mathbf{S}_{\mathbf{3}}$ The respondent shows that rejecting the antecedent $\left(\mathbf{e}^{\prime}\right.$ is $\left.\mathbf{A}^{\prime}\right)$ contradicts another tenet of the instigator, namely that the cognition in which two moons appear is "vividly appearing" (gsal snang). Indeed, being "vivid" is one of the characteristics of a non-conceptual cognition.

$\mathbf{S}_{\mathbf{3}}^{\prime}$ Parallel to this, the instigator shows that rejecting the antecedent (e is $\mathbf{A}$ ) in domain $\mathbf{D}$ is unacceptable as well. The reason given here relies on an argument occurring earlier in the text (which is also an argument by parallels), which shows that the perception e cannot be among the perceptions that are not valid cognitions; hence it must be accepted as a perception that is a valid cognition. ${ }^{19}$ $\mathbf{S}_{\mathbf{4}}$ The respondent, implicitly admitting that the antecedent (e is $\mathbf{A}$ ) cannot be rejected, states in accordance with $\mathbf{P}$ his acceptance of the consequent, namely, that $\mathbf{e}$ would then be intrinsically ascertained as valid (e is $\mathbf{X}$ ).

$\mathbf{S}_{\mathbf{4}}{ }_{\mathbf{4}}$ The instigator claims his acceptance of the parallel consequent in the domain of perception $\left(\mathbf{D}^{\prime}\right)$ : the cognition in which two moons appear is a perception $\left(\mathbf{e}^{\prime}\right.$ is $\left.\mathbf{X}^{\prime}\right)$. $\mathbf{S}_{\mathbf{5}}$ The respondent points to the fact that this consequent is refuted by the fact that $\mathbf{e}^{\prime}$ does not satisfy the instigator's own definition of perception.

$\mathbf{S}_{\mathbf{5}}{ }_{\mathbf{5}}$ The instigator states in parallel that the acceptance of the consequent in the domain of the ascertainment of validity (D) (e is $\mathbf{X})$ is refuted by the fact that $\mathbf{e}$ does not satisfy the definition of a cognition that is intrinsically ascertained as valid.

Here, $\mathbf{S}_{\mathbf{5}}$ and $\mathbf{S}_{\mathbf{5}}^{\prime}$ constitute the final stage of the argument. Indeed, once one reaches $\mathbf{S}_{\mathbf{5}}, \mathbf{e}^{\prime}$ has been established as a proper counter-example to $\mathbf{P}^{\prime}$ : it satisfies the antecedent $\left(\mathbf{e}^{\prime}\right.$ is $\left.\mathbf{A}^{\prime}\right)$, but not the consequent $\left(\mathbf{e}^{\prime}\right.$ is $\left.\mathbf{X}^{\prime}\right)$. Parallel to this, once one reaches $\mathbf{S}_{5}^{\prime}$, e has been established as a proper counter-example to $\mathbf{P}$ : it satisfies the antecedent (e is $\mathbf{A}$ ), but not the consequent (e is $\mathbf{X}$ ). Hence $\mathbf{S}_{\mathbf{5}}$ brings an end to the refutation of $\mathbf{P}^{\prime}$, and $\mathbf{S}_{\mathbf{5}}^{\prime}$ to the refutation of $\mathbf{P}$. Note that the refutation of $\mathbf{P}^{\prime}$ is not problematic insofar as the instigator does not actually subscribe to $\mathbf{P}^{\prime}$.

\footnotetext{
19 That not every perception is a valid cognition is a characteristic tenet of Phya pa's epistemology. It follows from his definitions of perception and valid cognition (see respectively n.18 and n.15) that there are two sorts of cognition that qualify as perceptions but not as valid cognitions. These are termed "unascertained appearance" (snang la ma nges pa) (they include, among other things, cases of inattentive cognition), and "[cognitions whose] object has already been known" (bcad pa'i yul can). The first sort does not fulfil the requirement of "eliminating opposite superimpositions", the second, the requirement of novelty. Still, both are non-conceptual and non-erroneous with regard to the apprehended state of affairs.
} 
If one separates the statements that pertain to the domain $\mathbf{D}$ and those that pertain to the domain $\mathbf{D}^{\prime}$, one can distinguish two intersecting arguments represented in the table below: in $\mathbf{T}$, the instigator (Phya pa) attacks the thesis $\mathbf{P}$, and in $\mathbf{T}^{\prime}$, the respondent (the Mīmāmsaka) attacks the thesis $\mathbf{P}^{\prime}$.

\begin{tabular}{|c|c|}
\hline T (D) Mìmāmssaka/Phya pa & $\mathbf{T}^{\prime}\left(\mathbf{D}^{\prime}\right)$ Phya pa/Mīmāṃsaka \\
\hline $\boldsymbol{P}=$ all $\boldsymbol{A}$ s are $\boldsymbol{X}$ & $\rightarrow \boldsymbol{P}^{\prime}=$ all $\boldsymbol{A}^{\prime}$ s are $\boldsymbol{X}^{\prime}$ \\
\hline $\mathbf{S}_{\mathbf{1}}^{\prime}$ : $\mathbf{e}$, which is $\mathbf{A}$, would be $\mathbf{X}$ & $\leftarrow \quad \mathbf{S}_{\mathbf{1}}: \mathbf{e}^{\prime}$, which is $\mathbf{A}^{\prime}$, would be $\mathbf{X}^{\prime}$ \\
\hline $\boldsymbol{S}_{2}: \boldsymbol{e}$ is not $\boldsymbol{A}$ & $\rightarrow \boldsymbol{S}_{2}^{\prime}: \boldsymbol{e}^{\prime}$ is not $\boldsymbol{A}^{\prime}$ \\
\hline $\begin{array}{l}\mathbf{S}_{3}^{\prime} \text { : if } \mathbf{e} \text { is not } \mathbf{A} \text {, it would be } \mathbf{B} \text { or } \mathbf{C} \text { and this has } \\
\text { absurd consequences }\end{array}$ & 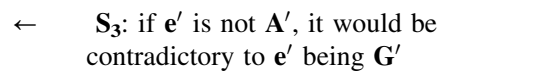 \\
\hline $\boldsymbol{S}_{4}$ : then $\boldsymbol{e}$ is $\boldsymbol{X}$ & $\rightarrow \mathbf{S}_{\mathbf{4}}^{\prime}$ : then $\mathbf{e}^{\prime}$ is $\mathbf{X}^{\prime}$ \\
\hline $\begin{array}{l}\mathbf{S}^{\prime}{ }_{\mathbf{5}}: \mathbf{e} \text { is not } \mathbf{X} \text {, because it does not have } \\
\mathbf{L}=\operatorname{def}(\mathbf{X})\end{array}$ & $\begin{array}{l}\mathbf{S}_{\mathbf{5}}: \mathbf{e}^{\prime} \text { is not } \mathbf{X}^{\prime} \text {, because it does not have } \\
\mathbf{L}^{\prime}=\operatorname{def}\left(\mathbf{X}^{\prime}\right)\end{array}$ \\
\hline
\end{tabular}

\section{The Function of Arguments by Parallels}

The majority of sections in which such arguments occur bear the heading "refutation [of the opponent's view]" (dgag pa; sun dbyung ba) or "rejection of objections" (rtsod pa spang $b a$ ). The function imparted by the instigator upon an argument by parallels dealing with a thesis $\mathbf{P}$ is hence to be understood as the refutation of $\mathbf{P}$, whether $\mathbf{P}$ represents the respondent's own position or an objection to the instigator's position. If $\mathbf{P}$ stands as an objection to a thesis that is to be proved by the instigator, or represents the opposite of the thesis to be proved, the refutation of $\mathbf{P}$ is considered to amount to the proper establishment of this thesis, and the argument by parallel is in such cases introduced under the heading "proof" (sgrub pa). ${ }^{20}$ Note that in either case the refutation of $\mathbf{P}$ stands as an implicit conclusion of the argument by parallels.

One may wonder why the instigator does not have recourse to the methods of proof and refutation that are prescribed in Buddhist logic, that is to say, inference (i.e., "inference-for-others") ${ }^{21}$ on the one hand, and reductio ad absurdum (Skt. prasanga, Tib. thal 'gyur) on the other. Moreover, considering the arguments $\mathbf{T}$ and $\mathbf{T}^{\prime}$ of our example, an obvious question is why the instigator does not just use $\mathbf{T}$ to establish his point, namely, why does he address $\mathbf{P}$ by stating $\mathbf{P}^{\prime}$ rather than by stating $\mathbf{S}_{\mathbf{1}}^{\prime}$ ? In order to answer these questions, let us try to characterize more precisely arguments by parallels and consider the overall strategy that directs their use.

\footnotetext{
${ }^{20}$ For instance in Phya pa Chos kyi seng ge (2006a, 89b6-90a2), under the paragraph entitled "proof [that there are] arguments by consequence in which only the entailment is expressed" (khyab pa tsam brjod pa'ithal 'gyur sgrub pa), the argument addresses a statement $\mathbf{P}$ that something else than the entailment must also be stated: "in order for an argument by consequence to be certain, it is necessary to express the fact that [the logical reason is a] property of the subject" (gzhan dag thal 'gyur la nges par phyogs chos brjod dgos so zhes zer ba).

21 The "inference-for-others" (parārthānumāna) consists in a set of statements that is meant to allow the opponent to generate an "inference-for-oneself" (svārthānumāna), i.e. to establish that the subject under discussion, which is known to be qualified by the relevant property stated as a logical reason, is also qualified by the property to be proved, on the grounds of a necessary relation established between the logical reason and the property to be proved (identity or causality).
} 


\subsection{Parity of Reasoning and Analogy}

I would suggest that there are two ways to conceive how an argument by parallels can lead the respondent to concede the refutation of $\mathbf{P}$ in view of the following fact: when considering $\mathbf{T}$ and $\mathbf{T}^{\prime}$ separately, the refutation of $\mathbf{P}$ stands as the implicit conclusion of $\mathbf{T}$, whereas when considering the sequence of statements in the argument by parallels, the refutation of $\mathbf{P}$ emerges as a conclusion that is parallel to the implicit refutation of $\mathbf{P}^{\prime}$. In the first case, since $\mathbf{T}$ and $\mathbf{T}^{\prime}$ display the same argumentative pattern, the respondent who accepts the probative, or rather, refutative power of $\mathbf{T}^{\prime}$ must also accept that of $\mathbf{T}$, by parity of reasoning. In this case, it is the "vertical" dimension of the argument that prevails, although it is supported by the "horizontal" dimension insofar as each of the key steps of $\mathbf{T}$ are introduced as parallels to the corresponding steps of $\mathbf{T}^{\prime}$. Let us note however that they do not logically depend on the latter. The reasons given for their establishment also do not logically depend on those given in $\mathbf{T}^{\prime}$ (whether or not these reasons take a parallel form $)^{22}$. One way to apprehend the strategy behind arguments by parallels is thus as follows: 1 . The instigator challenges the respondent with a (wisely chosen) thesis $\mathbf{P}^{\prime}$ in some domain $\mathbf{D}^{\prime}$. 2. The respondent catches the bait and generates an argument $\mathbf{T}^{\prime}$ leading to the refutation of $\mathbf{P}^{\prime}$. 3. The instigator applies an $\operatorname{argument} \mathbf{T}$ in domain $\mathbf{D}$ that reproduces, mutatis mutandis, all the steps of the argument $\mathbf{T}^{\prime}$. 4. The respondent must subscribe to the refutation of $\mathbf{P}$ by parity of reasoning. Otherwise, he is compelled to acknowledge a flaw in the reasoning he uses to refute $\mathbf{P}^{\prime}$, or is bound to admit $\mathbf{P}^{\prime}$. Let us note to this effect that such a strategy can work even if the respondent generates an argument $\mathbf{T}^{\prime}$ that is not valid (and there are actually a few instances of such cases in Phya pa's texts).

In the second perspective, the "horizontal" dimension of the argument by parallels takes precedence. The idea is then the following: if everything that is said about a set of elements of $\mathbf{D}^{\prime}$ holds also, mutatis mutandis, for corresponding elements in $\mathbf{D}$ (and vice versa), any conclusion that is conditioned by this set of elements in one domain also holds, mutatis mutandis, for the other domain. One can thus describe the process leading the respondent to the conclusion as a variety of analogical reasoning. "Analogy" is here to be understood not as similarity, but rather as considered in the light of the structure-mapping framework developed in recent studies, that discards the wide-spread opinion that analogy should involve elements of the same category (see Brown 1995) and instead gives prominence to the mapping of the relations between elements and to relations between relations over the mapping of properties of these elements (see Gentner 1983). In such a framework, the projection of conclusions (such as the application of a predicate) from a base domain (or source analogue) to a target domain that takes place in analogical reasoning is enabled by the structural alignment between the elements constitutive of each domain. Although there is a tendency to consider analogical

\footnotetext{
22 The reason given to establish the probative statements of $\mathbf{T}$ occasionally relies on a parallel, as for instance in $\mathbf{S}_{\mathbf{5}}^{\prime}$ : the definiens of $\mathbf{X}$ is introduced as a counterpart to the definiens of $\mathbf{X}^{\prime}$, and the reason, in both cases, relies on the same implicit rule that "what does not have the definiens cannot have the definiendum". In $\mathbf{S}_{\mathbf{3}}$ on the other hand, the reason given for the relation between $\mathbf{e}$ and $\mathbf{A}$ is not parallel to the one given for the relation between $\mathbf{e}^{\prime}$ and $\mathbf{A}^{\prime}$ in $\mathbf{S}_{\mathbf{3}}^{\prime}$.
} 
arguments as a type of ampliative and probabilistic reasoning, useful as a heuristic device, but unable to achieve certainty, some modern scholars defend the possibility of a "valid reasoning by analogy" (Weitzenfeld 1984) or of a "conclusive analogy" (Juthe 2005), or attempt to establish the sufficient criterion to establish the truth of an analogical inference (Davies and Russell 1987). André Juthe's study, in particular, contains elements that are relevant for our analysis of arguments by parallels. According to Juthe, there are two distinctions that can be made when characterizing arguments by analogy. The first distinction, between "good" arguments and "bad" arguments by analogy, relies on the isomorphism of the structures containing the elements that determine the application of the predicate that one wants to project, mutatis mutandis, to the target domain. The closer the structures are to being isomorphic, the better the analogy. ${ }^{23}$ Isomorphism amounts, in the system-mapping framework, to a structural alignment that satisfies complete one-to-one correspondence of the relevant elements, parallel connectivity (i.e. preservation of the relations between them) and systematicity (i.e. preservation of the relations between relations). The second distinction, between "conclusive" and "inconclusive" good arguments by analogy, is a function of the determination, in the base domain, of the conclusion that one wishes to project - an analogical argument is "conclusive" when the elements that determine the application of a predicate in the base domain determine it strictly (rather than through mere correlation). ${ }^{24}$

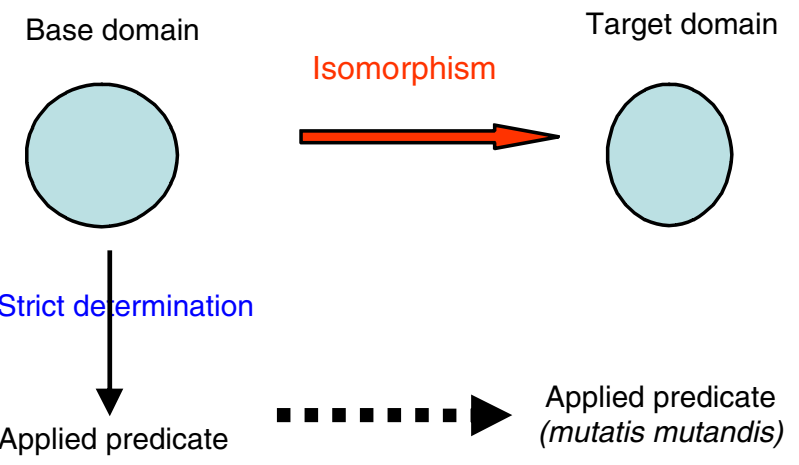

Returning to arguments by parallels, one can conceive that while the notion of isomorphism between the base and the target domain finds an equivalent in the "horizontal" dimension of the argument, Juthe's condition for a conclusive argument,

\footnotetext{
23 "The rule is that the extent of counterpart elements in common to the compared objects, will determine the range of the conclusion with the same proportion" (Juthe 2005, p. 9). "In a complete analogy there is a one-to-one correspondence between all the elements of the objects of comparison and any justified conclusion from the Analogue will be (mutatis mutandis or not) justified about the TargetSubject as well" (ibid., p. 10).

24 "The conclusion can be said to follow conclusively from the analogy even if it is not in virtue of logical necessity" (Juthe 2005, p. 11). See also Weitzenfeld (1984, p. 141): "[C]onclusions will follow apodeictically from a genuine isomorphism". And further (ibid. 141): "Any set of relations defined on a set of elements can constitute a structure, and any isomorphism between structures can support valid inferences, but the modality, or ontological status, of the relations comprising a structure is very important both for the means of establishing the existence of the structure and for the range of inferences it will license." See also Davies and Russell (1987, p. 4) for a definition of the "determination rule."
} 
i.e. the strict determination of the applied predicate in the base domain, would find for its part an equivalent in the "vertical" dimension, for, by generating the argument $\mathbf{T}^{\prime}$, the respondent determines in which way the structure of the relevant elements of domain $\mathbf{D}^{\prime}$ supports the conclusion, i.e., the refutation of $\mathbf{P}^{\prime}$. Now, what happens in an argument by parallels is that the isomorphism of the two domains is established by enumeration. Therefore, the conclusion for $\mathbf{D}$ does not have to be derived from the conclusion reached for $\mathbf{D}^{\prime}$, it can simply be derived from $\mathbf{T}{ }^{25}$

The two persepctives that I initially distinguished hence turn out to be akin, although with different foci: The "parity of reasoning perspective" emphasizes the pattern of argumentation that leads to the conclusion, and thereby the role of the respondent who generates this pattern for the parallel domain $\mathbf{D}^{\prime}$. The "analogical perspective" puts the emphasis on the parallelism between the structures of the corresponding elements in $\mathbf{D}$ and $\mathbf{D}^{\prime}$ - for instance in our example the relations between the elements $(\mathbf{e}, \mathbf{A}, \mathbf{X})$ and between the elements $\left(\mathbf{e}^{\prime}, \mathbf{A}^{\prime}, \mathbf{X}^{\prime}\right)$ - and on the role of the instigator, whose seemingly automated replies now appear as a means to establish the putative isomorphism between the two domains. The instigator has to choose the counterpart-elements and to establish the conservation of their structure. This, in turns, is necessary to guarantee the applicability in $\mathbf{D}$ of the pattern of reasoning used in $\mathbf{T}^{\prime}$. Indeed, although the respondent should not object to the pattern of $\mathbf{T}$ as such, he can, and does in some cases (such as in the argument under consideration here), object to the conditions for its application. For instance in our example, the respondent, although he agrees that the existence of a counter-example refutes the contention of a universal relation, objects that $\mathbf{e}$ is a counter-example to $\mathbf{P}$ like $\mathbf{e}^{\prime}$ is a counter-example to $\mathbf{P}^{\prime}$.

\subsection{The Status of the Conclusion}

What is the status of the implicit conclusion of an argument by parallels? Juthe contends that in a good, conclusive argument by analogy, the conclusion has the same certainty as that of a deductive argument, albeit this certainty does not have the same source. ${ }^{26}$ This certainty is grounded in the strict determination of the application of the predicate in the source domain. In this perspective, in argument by parallels, the status

\footnotetext{
25 In analogical arguments, the establishment of the isomorphism threatens the relevance of using an analogy in the first place. Weitzenfeld (1984, p. 146) proposes that an isomorphism can be known by enumeration, surveillance, or inference, and he says about the first one: "By and large this is not a promising way to learn anything, since any knowledge that is to be inferred from the isomorphism must be discovered in the process of enumeration before the isomorphism is known." Davies and Russell, who have a specifically computer-related goal, namely "to provide a reliable, programmable strategy that will enable a system to draw conclusions by analogy only when it should" (Davies and Russell 1987, p. 1), deal with the above question under the name of "non-redundancy problem", and they express it as follows: "The background knowledge that justifies an analogy or single-instance generalization should be insufficient to imply the conclusion given information only about the target. The source instance should provide information not otherwise contained in the database" (ibid., 2).

26 Juthe (2005, p. 19): “[T]he conclusion follows conclusively but not deductively. It would not be a logical incoherence to deny the conclusion at the same time as one affirms the premises of an argument by conclusive analogy."
} 
of the conclusion would be a function of the argument developed by the respondent for the parallel domain $\mathbf{D}^{\prime}$. From the point of view of the appeal to parity of reasoning, it is a function of $\mathbf{T}^{\prime}$ as well. Still, the certainty of the conclusion relies on the existence of the putative isomorphism of the two domains, which, alone, can guarantee that the premisses of $\mathbf{T}$ are true. When these conditions are met, the conclusion is certain, but insofar as it could be established by $\mathbf{T}$ independently, the introduction of the parallel is useless from a logical point of view.

The technique of systematic parallels turns out to be convenient if $\mathbf{T}$ itself involves a flaw, or a difficulty. This is actually the case in our example: First, let us consider the reason given in $\mathbf{S}_{\mathbf{3}}^{\prime}$ for $\mathbf{e}$ being an $\mathbf{A}$, namely for showing that the counter-example satisfies the antecedent. This reason relies on Phya pa's typology of perceptual cognition, which is quite idiosyncratic even among Buddhist logicians. Next, the argument given in $\mathbf{S}^{\prime}{ }_{\mathbf{5}}$ for $\mathbf{e}$ not being an $\mathbf{X}$ relies on the fact that $\mathbf{e}$ does not have $\mathbf{L}$, which is the definiens of $\mathbf{X}$. This reason comes as a parallel to the one given by the respondent in $\mathbf{S}_{\mathbf{5}}$ for $\mathbf{e}^{\prime}$ not being an $\mathbf{X}^{\prime}$, namely, that $\mathbf{e}^{\prime}$ does not have $\mathbf{L}^{\prime}$, which is the definiens of $\mathbf{X}^{\prime}$. If we look closer, we notice that $\mathbf{L}$ is the definiens of $\mathbf{X}$ only according to Phya pa. Thus what $\mathbf{T}$ actually establishes is that $\mathbf{P}$ must be rejected by someone who admits Phya pa's typology of perceptual cognitions and his definition of intrinsic ascertainment. But for a respondent who does not subscribe to Phya pa's system in the first place, $\mathbf{T}$ is not a sound argument because its premises are not held to be established. It is thus conceivable that the parallel argumentation, which introduces the problematic (putatively probative) statements of $\mathbf{T}$ as parallels rather than as independent statements, is used here as a way to conceal this weakness.

I have noted earlier that arguments by parallels can also be successful if the respondent generates an argument $\mathbf{T}^{\prime}$ that is not valid. In both cases, although it is possible that the respondent concedes the refutation of $\mathbf{P}$, this conclusion does not have the certainty that is required of a logical argumentation. Nevertheless, Phya pa does not seem to consider that the conclusion that is reached in such cases has less certainty than the ones derived from the otherwise prescribed methods of proof and refutation. He thus seems to be granting argumentation by parallels the status of a logical argumentation, and not merely that of a discursive technique. Contrastively, one can note that a later author, Sa skya Paṇdita (1182-1251), distinguishes explicitely in his argumentation what consistutes a "real answer" (dngos po'i lan) to an objection from other techniques, such as the equivalent of tu quoque argumentation (presented in terms of mgo mtshungs kyis dgag pa), which are thereby ascribed a lesser status. ${ }^{27}$

\subsection{The Benefits of Argumentation by Parallels}

In view of the rhetorical strategy in play, arguments by parallels can be shown to have several advantages. The first one, as came out of the above discussion, is that it adds a convincing weight to an otherwise sound argument, or makes up for a flaw in an argument. One can in addition distinguish the following profits:

\footnotetext{
27 See Sa skya Pandita Kun dga' rgyal mtshan: (1989, 106-109).
} 


\subsubsection{A Double Task for the Respondent}

One of the roles of the respondent in the argument by parallels amounts to the generation of an argument $\mathbf{T}^{\prime}$ from which the instigator derives the argument $\mathbf{T}$. As one can see when comparing $\mathbf{T}$ to $\mathbf{T}^{\prime}$, it is the respondent who provides the points that bring about the conclusion of $\mathbf{T}^{\prime}$, namely the refutation of $\mathbf{P}^{\prime}$. Their parallels in domain $\mathbf{D}$, for their part, support the conclusion of $\mathbf{T}$, and therewith the refutation of the respondent's initial thesis. In brief, it is the respondent who provides the instigator with the means to refute him!

As $\mathbf{T}$ and $\mathbf{T}^{\prime}$ are intermingled in the argument by parallels, the respondent does not only deal with $\mathbf{T}^{\prime}$, but also objects to the successive steps of $\mathbf{T}$ reached by the instigator, hence defending his claim $\mathbf{P}$ against the instigator. The objections that the respondent raises in the course of the argument by parallels are not different from those that he would raise when $\mathbf{T}$ is stated as an independent argument. However, due to the structure of the argument, the respondent is bound to experience what I call a "boomerang effect". Namely, just as every argument he gives against $\mathbf{P}^{\prime}$ comes back as an argument against $\mathbf{P}$, each of his arguments in defence of $\mathbf{P}$ comes back as a defence of $\mathbf{P}^{\prime}$ that he has to address. But by doing so, he provides the instigator with an answer to every objection against $\mathbf{T}$. Hence the respondent is not only providing the instigator with an argument against $\mathbf{P}$, he also (indirectly of course) secures it against any objection.

The instigator's actions are limited to 1 . motivating a reaction from the respondent in the first place, and 2. drawing parallels from the respondent's statements. By doing so, the instigator succeeds not only in keeping the respondent under the burden of proof, but even better, gets the respondent to come up with an argument that will work against his own position and can resist all objections. That $\mathbf{P}^{\prime}$ ends up being refuted in the process is not a problem for the instigator, for it did not represent his own accepted position in the first place, but was only designed to reveal the falsity of $\mathbf{P}$.

Hence it is obviously advantageous for an instigator to initiate this type of argumentation. It can moreover be seen as a good technique for a debater who does not know how to refute a thesis $\mathbf{P}$ in a live debate. More charitably, the instigator can also be thought to be using this technique as a pedagogical device. The question, which I will address in Sect. 4.1, remains why any sensible respondent would willingly engage in such a type of self-defeating debate.

\subsubsection{The Parallel Domain as an Example}

One can also consider that the parallel domain is introduced to play the role of an example with regard to the application of a rule of reasoning. Examples are notoriously famous in Buddhist logic for their use in inference, in particular the type of inference termed "inference-for-others", in which the proponent verbally presents the opponent with the evidence that will allow him to establish a certain property for the subject under discussion. There, examples serve as a device that allows the addressee of the inferential reasoning to remember the entailment 
between the logical reason given as evidence and the property to be proved. ${ }^{28}$ Whereas the example in an inference-for-others is an object instantiating a relation (for instance the example 'kitchen' when inferring fire from the presence of smoke), the parallel domain in an argument by parallels is a set of elements instantiating a structure (i.e. relations between elements and higher-order relations). It can thus provide the basis for the application of logical operations that are more complex than entailment between two properties. ${ }^{29}$ It must be noted that in the majority of cases the rule or reasoning itself, in an abstract form, as well as the identification of the relation between the elements (for instance definiens-definiendum, cause-effect, etc.) are not made explicit in the course of the argument by parallels, which goes from a particular application to another particular application. ${ }^{30}$

A point in support of the parallel domain playing the role of an example is the fact that some cases of arguments by parallels occurring in Phya pa's Dispeller are transformed in the Sunray of Wisdom into an argument of an explanatory type that does not involve an initial retort, nor the structure that follows from it. There, the other domain is introduced as an example in a way similar to the statement of the example in an inference-for-others. ${ }^{31}$

\footnotetext{
${ }^{28}$ On "inference-for-others", see n. 21 as well as T. Tillemans' introduction to this volume. For more information on the use of examples, see Katsura and Steinkellner (2004).

${ }^{29}$ With regard to this idea, it is interesting to note that in recent years analogy has been used for developing computational systems that are able to prove target theorems, i.e. to develop a "target proof" on the basis of a given source theorem established by a source proof (Melis 1996). Analogy is also used in the process of "retrieving" the solution to a problem from a prior analogous example (Gentner 1998). Similarly, in the argument by parallels, one could say that the instigator is inviting the respondent to retrieve the argument generated for $\mathbf{D}^{\prime}$ in order to apply it to $\mathbf{D}$, but with the important nuance that the
} respondent first has to generate the argument for $\mathbf{D}^{\prime}$.

30 The general rule is made explicit on very few occasions in the Dispeller. In one instance for example, one finds the rule "by refuting the definiens one refutes the application of the definiendum". This rule is explicitly given after the presentation of the parallel statement. Namely, the statement "when one refutes that it (i.e. the inference of the property 'impermanent' from the property 'being an object of cognition') is an inference generally speaking because there is no comprehension issued from a triply characterized reason, one also refutes that it is a valid inference" (de la tshul gsum pa'i rtags las rtogs pa med pas rjes dpag tsam khegs pa na rjes dpag tshad ma'ang khegs so zhe na), is replied to by the instigator as follows: "In the case of the apprehension of a conch as yellow, etc., as well, when one refutes that it is a perception generally speaking because there is no being non-erroneous with regard to the apprehended state of affairs, one also refutes that it is a valid perception, because when one refutes the definiens, one also refutes the definiendum" (dung ser por 'dzin pa lasogs pa la'ang gzung pa'i don la ma 'khrul ba med pas mngon sum tsam khegs pa na mngon sum tshad ma'ang khegs pa yin te mtshan nyid khegs na mtshon bya'ang khegs pa'i phyir ro). See Phya pa Chos kyi seng ge (2006a, 34a6-34a7).

${ }^{31}$ See for instance the argument about the validity of inference mentioned above (see n.11). In contrast, in the Sunray of Wisdom, Phya pa answers to the same objection as follows: "being a valid cognition (=the understanding of something true) is not an independent property but depends on the object; therefore although it (i.e., inference) is a wrong cognition with regard to the apprehended object, it is not contradictory with its being a valid cognition with regard to the object of application. Just like it is not contradictory that fire is a cause with regard to smoke, although it (i.e. the fire) is subsequent with regard to the fire-wood" (Phya pa Chos kyi seng ge (2006b, 78a6-78a7): gzhan dag gis rjes su dpag pa ni gzung yul don spyi la ltos nas log pa' $i$ shes pa yin pa'i phyir tshad mar myi 'thad do zhes rgol ba na tshad ma ni dag pa ba ma yin te | yul la ltos pa' $i$ chos yin pas gzung yul la ltos nas log shes yin yang 'jug la ltos nas tshad ma yin pa myi 'gal te $\left.\right|_{78 a} 7$ mye de bud shing las ltos nas phyis 'byung yin yang du ba la ltos na rgyur myi 'gal ba bzhin no zhes gzhan gyi gnod pa spong ba ni...). 


\subsubsection{Explanatory Device}

For the author of a text, an argument by parallels can be used as an explanatory, or even pedagogical device, for it allows him to make a detailed presentation of his position while contrasting it with a false understanding. This possibility is opened to the author either as an instigator, especially against an objection to his own views, or as a respondent addressing a putative parallel. In addition, the author's presentation beneficiates, on a didactical level, from the support of a parallel, more familiar domain, in which the various relations between elements can be more easily grasped by a reader or an opponent. This feature of arguments by parallels might not be obvious in the example we analyzed, where both domains involve quite "technical" notions. Its pedagogical benefit might be clearer when considering the example, cited in Sect. 2.1.1, of the retort introducing sprouts and seeds in answer to the objection concerning inference. The parallel domain makes use of the familiar notions of "before" and "after", and "seed" and "sprout" to illustrate how notions such as "cause" and "effect" are always to be considered in function of an object: the sprout is not the cause of the seed, but this does not prevent it from being the cause of a visual perception. The author's views on inference can be explicitated on the basis of this comprehension: the notions of "correct" and "incorrect" also must be understood in function of an object; inference might not be correct with regard to the apprehended object, but this does not prevent it from being correct with regard to the object of application. Here, thanks to the parallel domain, the author can point to a part of the structure of the domain of inference that was not explicit in the original objection-thesis $\mathbf{P}$, namely that two objects have to be taken into consideration, and that only one of them is relevant to decide on the validity of inference.

\section{Arguments by Parallels in the Framework of Indo-Tibetan Logic}

\subsection{The Plausibility of a Two-Voiced Parallel Argument}

In view of the form of arguments by parallels, which is that of a dialogue, one may wonder if their use originated in oral debate. We do not have any evidence that such arguments actually took place in oral debate at the time of Phya pa, and there remains the question, raised before in Sect. 3.3, of the plausibility that a respondent would actually "go along" with the process and actually answer an initial retort and the subsequent systematic parallels in the above-described way, instead of refusing from the start to enter into a discussion pertaining to an unrelated domain $\mathbf{D}^{\prime}$.

One point is clearly in favour of such a possibility: Although it would appear that the respondent merely fulfils a heavy and non-gratifying task in an argument by parallels, its structure grants him one power that the instigator does not have: the respondent can choose the course of the argument whereas the instigator can only proceed with parallel statements. Hence, by choosing pertinent replies the respondent has the possibility to make the argument unsuccessful for the instigator. We see that this is precisely what Phya pa does when he is faced with a retort. Additionally, he even takes the opportunity to expound on his views in the process. 
One technique used by Phya pa to this effect when he is the respondent is to give a response in the form of a question such as "Why do you state $\mathbf{P}^{\prime}$ ?" or "What is the reason for $\mathbf{P}^{\prime}$ ?". The instigator, who has to play by the rules, has no choice but to retort in parallel: "Why do you state $\mathbf{P}$ ?" or "What is the reason for P?". This gives the respondent (i.e., Phya pa) the opportunity, in the next step, to explain why he holds $\mathbf{P}$. The structure of the elements of the domain $\mathbf{D}$ is then presented according to his own views rather than those of the instigator, and it becomes possible, at some point, to reach the conclusion "it is not the same."

\subsection{Oral Arguments and Written Arguments}

Even if we can envisage the arguments by parallels found in Phya pa's works as mirroring an oral practice, written arguments found in a treatise cannot be considered simple transcripts of oral debates, despite their dialectical form. In both cases, the instigator's argument has two addressees: the opponent (i.e., the respondent) and the public (or the reader or listener of the treatise). But there is an important difference: in a live debate, the principal addressee is the opponent, a real debater who plays an active role. In a written argument on the other hand, the author, when initiating a dispute, also takes the voice of the respondent. The choice of the response, what is said or left unsaid, the objections raised, addressed or ignored-all this falls within the competence of the author, and is indicative of another difference: in the case of a treatise, it is the reader (or listener) who has become the principal addressee. Thus the author's assumptions about the reader's knowledge, about his possible agreement with the opponent's tenets, etc., play a major role in his choice of formulation of an argument. For instance, in the argument we analyzed above, it is quite obvious that the respondent's statements are from the hand of the author, considering (notwithstanding the fact that there were no Mīmāmsaka in Tibet and that the Mīmāmssaka did not know Phya pa's view on perception) that the respondent could have brought the argument to another outcome with different answers. Moreover, with or without the introduction of the parallel domain, Phya pa's argument would most probably never have convinced a Mīmāmsaka insofar as, as I have shown above, its putative probative steps are themselves problematic. But I would suggest that this was not its role: although Phya pa does have to address the Mīmāmsaka tenet if he wants to be able to claim in his treatise that "all the other positions have been refuted", his goal is not to convince the Mīmāmsaka that his position is wrong, but to convince the reader that the Mīmāmsaka's position is wrong. And the intended reader is here clearly an adherent of Phya pa's system.

\subsection{Theory and Practice}

Although Phya pa makes abundant use of arguments by parallels, a theoretical presentation of them is not included in his chapter entitled "the way to talk in the context of disputation" (rtsod pa'i ngag gi tshul), nor anywhere else in his epistemological works. A systematic presentation is also not found in the works of his Indian and Tibetan predecessors or in those of his disciples, where even the use 
of such arguments becomes scarcer. ${ }^{32}$ The closest we come to a theoretical comment about arguments by parallels is Phya pa's remark, following his citation of such an argument used by one of his predecessors, qualifying the parallel as a "true similarity" (mtshungs pa bden) (Phya pa Chos kyi seng ge 2006a, 43b7). The isolated use of the expressions cha mthun gyi mgo bsgre ("an analogue parallel", or "a conducive retort") and thod rgal pa'i mgo bsgre (literally "angry parallel") by Sa skya Pandita also hints at the existence of a technical vocabulary related to the evaluation of arguments by parallels. ${ }^{33}$

Whether we consider the practice of debate or written treatises, the use of arguments by parallels appears to conflict with the means of proof and refutation described and prescribed in the works of Dharmakirti and adopted by his Indian and Tibetan epigones. In particular, they contravene to the duties ascribed to the proponent (snga rgol) and opponent (phyi rgol) when entering a philosophical debate. These are, in summary, to present correct arguments, and to duly point out the faults in the other debater's argumentation. The structure of arguments by parallels would at most resemble that of the so-called "six-winged disputation" (șatpakși kathā) discussed in Gotama's Nyāyasütra 39-43, in which one (or both) of the opponents, instead of rejecting the criticism aimed at his position, invokes as an argument that the same fault occurs for the opponent. This, according to the author of the Nyāyasuttra, is a paradigmatic case of a futile debate, for the debater (or both

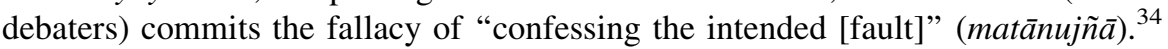

The occurrence of arguments by parallels even in treatises that prescribe the rules of debate to be followed (not mentioning arguments by parallels in the process), would support the conjecture that these rules were above all "ideal rules of debate" which, in practice, did not exclude the use of a broader range of argumentative techniques involving not only dialectical but also rhetorical, pedagogical and explanatory functions.

\footnotetext{
32 As for Phya pa's predecessors, the only epistemological works available are those of rNgog Blo ldan shes rab (1059-1109?), where I have not as yet found occurrences of arguments by parallels. Phya pa reports the use of such arguments by unidentified predecessors, but we lack first-hand evidence. They are merely designated as "some", "others", "some of our bla ma", "some ancient learned ones", and even as "some who think they are excellent although they are of small intellect". In the absence of more precise identification and of the works concerned, the question remains as to whether we are dealing with a literal account, or if Phya pa is "reformatting" their arguments. As for Phya pa's successors, I have not extensively searched for such arguments in post fourteenth century works, but one can note for instance that mKhas grub rje (1385-1438) occasionally resorts to arguments called "rigs sgre", whose first step corresponds to a "mtshungs pa", but which do not display the complete features of arguments by parallels.

33 See Sa skya Pandita Kun dga’ rgyal mtshan, (1989, 183-184).

34 See Gotama (1990). Such an argument can follow from the use of "analogues" (sama) that constitute futile rejoinders $(j \bar{a} t i)$. For instance, to someone who proves that "sound is non-eternal because it is a product, like a pot", one can oppose a futile rejoinder in the form of the following analogue: "sound is eternal, because it is incorporeal, like ether". The futile rejoinder rests on the similarity in the two cases of the homogeneity between the subject (sound) and the example (respectively, pot and ether). It is "futile", because unlike a pot, which exemplifies an invariable connection between product-ness and noneternality, ether does not exemplify an invariable connection between incorporeality and eternality. Once the original proposition and the rejoinder have been stated, the proponent can point out the fault in the rejoinder. At this point, if the opponent urges that the same fault occurs in the original proposition, he admits by doing so that the fault does occur in his own position.
} 
Acknowledgements My thanks to Mrs. Cynthia Peck-Kubaczek for correcting my English and to the participants of the ISSA panel on Buddhist Argumentation for their useful comments.

\section{Appendix: Tibetan Text and Translation}

Dispeller (Phya pa Chos kyi seng ge 2006a, 35b8-36a2)

$\mathbf{P}$ spyod pa ba lasogs pa tshad ma thams cad rang las ${ }_{35 \mathrm{~b} 9}$ nges 'dod pa dag la ${ }^{\prime}$ de ltar na rtog med thams cad mngon sum yin no zhes bsgre'o I

$\mathbf{S}_{1}$ 'o na zla ba gnyis snang yang rtog med yin pas mngon sum du thal lo zhe na $\left.\right|^{\mathbf{S}^{\prime}}{ }$ me snang par nges kyang bden par ma nges pa'ang tshad ma yin pas rang nges su thal lo I

$\mathbf{S}_{\mathbf{2}}$ de tshad ma nyid ma yin no zhe na $\left.\right|^{\mathbf{S}_{2}}$ zla ba gnyis snang rtog med ma yin no $\mid$

$\mathbf{S}_{3}$ 'o na gsal snang du 'gal lo zhe na $\mathbf{S}^{\mathbf{S}^{\prime}}{ }$ tshad ma ma yin na $36 \mathrm{a}$ snang la ma nges pa 'am bcad pa'i yul can gang rung du 'gyur na sngar bshad pa'i nyes pas gnod do I $\mathbf{S}_{4}$ rang nges su thal ba 'dod do zhe na $\left.\right|^{\mathbf{S}^{\prime}}{ }^{4}$ mngon sum du thal ba' ang 'dod do I

$\mathbf{S}_{\mathbf{5}}$ gzung don la ma 'khrul ba bkag pas mngon sum khegs so zhe na $\mathbf{S}^{\mathbf{S}^{\prime} \mathbf{5}}$ yul sgro btags su dogs pa na 'dzin pa don la mi 'khrul pa'i rnam par ma nges te tshad ma'i mtshan nyid dang ldan par rdzas de nyid kyis ma nges pas rang nges khegs $36 a_{2}$ pa yin no II

$\mathbf{P}$ To the Mīmāmsaka and others who accept that all valid cognitions are intrinsically ascertained [as valid] ${ }^{\mathbf{P}^{\prime}}$ we retort: “in that case, all non-conceptual cognitions are perceptions".

$\mathbf{S}_{\mathbf{1}}$ If it is said that it would absurdly follow that the appearance of two moons also would be a perception on the grounds that it is non-conceptual, ${ }^{\prime}{ }^{\prime}$ [we reply] that it would absurdly follow that [a cognition] that ascertains that fire appears but does not ascertain its [objective] truth also would be intrinsically ascertained on the grounds that it is a valid cognition.

$\mathbf{S}_{\mathbf{2}}$ If it is said that this [cognition] is not a valid cognition, $\mathbf{S}^{\prime}{ }_{2}$ [we reply] that the appearance of two moons is not non-conceptual.

$\mathbf{S}_{\mathbf{3}}$ If it is said that it is contradictory to the fact that it (i.e. two moons) appears clearly, ${ }^{\mathbf{S}_{\mathbf{3}}}$ [we reply] that if it (i.e. the cognition that ascertains fire, but not its truth) is not a valid cognition, and would be instead either an unascertained appearance or the cognition of something already known, it is refuted in view of the faults previously explained.

$\mathbf{S}_{\mathbf{4}}$ If it is said that one accepts the consequence that it (i.e. the cognition that ascertains fire, but not its truth) is intrinsically accepted, ${ }^{\prime}{ }^{\prime}{ }$ [we reply] that we, for our part, also admit the consequence that [the appearance of two moons] is a perception.

$\mathbf{S}_{\mathbf{5}}$ If it is said that its (i.e. the appearance of two moons) being a perception is rejected, because one rejects that it is non-erroneous with regard to the apprehended

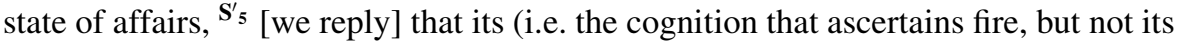
truth) being intrinsically ascertained as valid is rejected for the following reason: when there is doubt as to whether the object is superimposed, the apprehending cognition is not ascertained as being non-erroneous with regard to a state of affairs, and is consequently not being ascertained through that substance (i.e. cognition) itself as possessing the definiens of valid cognition. 


\section{References}

Brown, William R. 1995. The domain constraint on analogy and analogical argument. Informal Logic 17.1: $89-100$.

Davies, Todd R., and Russell, Stuart J. 1987. A logical approach to reasoning by analogy. In Proceedings of the tenth international joint conference on artificial intelligence, Morgan Kaufmann, Milan.

Gentner, Dedre. 1983. Structure-mapping: A theoretical framework for analogy. Cognitive Science 7, 155-170, reprint in A. Collins, and E. E. Smith, eds. Readings in cognitive science: A perspective from psychology and artificial intelligence. Palo Alto, CA, Kaufmann.

Gentner, Dedre. 1998. Analogy. In A companion to cognitive science, eds. Bechter W., and G. Graham, 107-113 Oxford: Blackwell.

Goldstein, Melvyn C., et al., eds. 2001. The new Tibetan-English dictionary of modern Tibetan. Berkeley, Los Angeles: University of California Press.

Gotama. 1990. Nyāyasūtra, Sanskrit text, ed. Nanda Lal Sinha, and M.M. Satis Chandra Vidyābhūṣaṇa, Allahabad, 1930, reprint in Delhi: Motilal Banarsidass.

Hugon, Pascale. Forthcoming. Phya pa Chos kyi seng ge's views on perception. In Proceedings of the 4th Dharmakirti Conference, 23-27 August 2005, Vienna, Verlag der Österreichischen Akademie der Wissenschaften, Vienna.

Jäschke, Heinrich August. 1995. A Tibetan-English dictionary, London, 1881, reprint in Delhi: Motilal Barnasidass.

Juthe, André. 2005. Argument by analogy. Argumentation 19: 1-27.

Katsura, Shōryū, and Ernst Steinkellner, eds. 2004. The role of the example (dṛțānta) in classical Indian logic, Wiener Studien zur Tibetologie und Buddhismuskunde 58, Arbeitskreis für tibetische und buddhistische Studien, Vienna.

Klong chen Rab 'byams pa (attributed to). 2000. Tshad ma'i de kho na nyid bsdus, ed. Padma tshul khrims, Si khron mi rigs dpe skrun khang, Chengdu.

Melis, Erica. 1996. 'When to prove theorems by analogy?' In KI-96: Advances in artificial intelligence. 20th annual German conference on artificial intelligence, Lecture notes in artificial intelligence 1137, 259-271. Berlin: Springer Verlag.

Oberhammer, G., et al. 1991. Terminologie der frühen philosophische Scholastik in Indien, ein Begriffswörterbuch zur altindischen Dialektik, Erkenntnislehre und Methodologie, Band 1: A-I, Verlag der Österreichischen Akademie der Wissenschaften, Vienna.

Phya pa Chos kyi seng ge. 2006a. Tshad ma yid kyi mun sel ["Dispeller"], in bKa' gdams gsung 'bum phyogs sgrig thengs dang po|dpal brtsegs bod yig dpe rnying zhib 'jug khang nas bsgrigs, vol. 8, Si khron mi rigs dpe skrun khang, Chengdu.

Phya pa Chos kyi Seng ge. 2006b. Tshad ma rnam par nges pa'i 'grel bshad yi ge dang rigs pa'i gnad la 'jug pa'i shes rab kyi 'od zer ["Sunray of Wisdom”], in bKa' gdams gsung 'bum phyogs sgrig thengs dang po|dpal brtsegs bod yig dpe rnying zhib 'jug khang nas bsgrigs, vol. 8, Si khron mi rigs dpe skrun khang, Chengdu.

Sarat Chandra Das, Rai Bahadur. 1992. A Tibetan-English dictionary, Calcutta, 1902, reprint in Delhi: Book Faith India.

Sa skya Pandita Kun dga' rgyal mtshan. 1989. Tshad ma rigs pa'i gter and Tshad ma rigs pa'i gter gyi rang gi 'grel pa, ed. by Nor brang o rgyan, Bod ljongs mi dmangs dpe skrun khang, Lhasa.

Stcherbatsky, Theodore. 1994. Buddhist Logic, 2 vols., Bibliotheca Buddhica, Leningrad, 1932, reprint in Delhi: Motilal Banarsidass.

van der Kuijp, Leonard W.J. 1978. Phya-pa Chos-kyi Seng-ge's impact on Tibetan epistemological theory. Journal of Indian Philosophy 5: 355-369.

van der Kuijp, Leonard W.J. 1983. Contributions to the development of Tibetan Buddhist epistemology. Wiesbaden: Franz Steiner.

Vasubandhu. 1967. Abhidharmakośa and Abhidharmakośabhāṣya, Sanskrit texts edited by Pralhad Pradhan, Kashi Prasad Jayaswal Research Institute, Patna, India.

Weitzenfeld, J.S. 1984. Valid reasoning by analogy. Philosophy of Science 51: 137-149.

Zhang, Yisun. 1985. Bod rgya tshig mdzod chen mo/Zanghan dacidian. Mi rigs dpe skrun khang/Minzu chubanshe, Beijing. 